\title{
Las independencias en el norte del Perú: la intendencia de Trujillo y la opción patriota (1820-1823)
}

\author{
por \\ Elizabeth Hernández García ${ }^{1}$ \\ Universidad de Piura, Campus Lima/Instituto Riva-Agüero
}

\begin{abstract}
Este artículo es una propuesta de análisis del proceso de independencia de Trujillo, es decir del espacio norte peruano, en su conjunto. Los aspectos tratados giran en torno a la existencia de un discurso político previo de afirmación de la localidad; los acontecimientos que condicionaron el cambio a la opción patriota; las proclamaciones de independencia y las contrarrevoluciones; los liderazgos locales; los enfrentamientos políticos entre los partidos de la intendencia de Trujillo en el Perú ya independiente; y las reivindicaciones regionales en la relación entre Trujillo y la capital de la república del Perú. Teniendo en cuenta estas perspectivas, se busca ir más allá de la consideración de una región norte que fue la primera en proclamar su independencia en el contexto nacional. En el camino tanto a la proclamación como a la consolidación de la independencia nacional, la intendencia de Trujillo no fue una entidad uniforme.

Palabras Clave: intendencia; Trujillo; norte peruano; independencia; Perú; revolución; contrarrevolución.

Cómo citar este artículo / Citation: Hernández García, Elizabeth, "Las independencias en el norte del Perú: la intendencia de Trujillo y la opción patriota (1820-1823)", Revista de Indias, LXXXI/281 (Madrid, 2021): 83-114. https://doi.org/10.3989/revindias.2021.003.
\end{abstract}

José de la Serna, el último virrey del Perú, abandonó la capital a inicios de julio de 1821 con dirección a la sierra central a rearmar su ejército y esperar mejores condiciones para enfrentarse luego a las fuerzas patriotas. Esta decisión sumió a la población de Lima en una sensación de gran inquietud, miedo, desolación y desconcierto. Estando así las cosas, y en con-

\footnotetext{
${ }^{1}$ elizabeth.hernandez@udep.edu.pe,_ORCID iD: https://orcid.org/0000-0003-3856-3362
} de uso y distribución Creative Commons Reconocimiento 4.0 Internacional (CC BY 4.0). 
moción los vecinos por los saqueos de la plebe los días siguientes a la partida del virrey, solicitaron la entrada de José de San Martín a la capital para pacificar la ciudad y recuperar la tranquilidad. Una avanzada del ejército libertador ingresó a Lima y, poco después, San Martín entró a la Ciudad de los Reyes. Su plan de conquista de Lima se había cumplido a cabalidad. San Martín pidió al cabildo de Lima que manifestase si la causa del Perú estaba inclinada hacia la independencia. Todo pasó muy rápido. No se hizo la consulta a todos los pueblos - como sí ocurrió en otras partes de América $^{2}$ - , sino que se decidió en virtud de las circunstancias. Así, el 15 de julio de 1821, en cabildo abierto, los limeños declararon positivamente a favor de la causa patriota ${ }^{3}$. Días después, el 28 de julio, José de San Martín proclamaba la independencia del Perú en la ciudad de Lima. Este último acto, de enorme simbolismo y ritualidad ${ }^{4}$, buscaba manifestar el inicial triunfo de los patriotas sobre los realistas en un momento medular dentro de la historia de la independencia peruana y americana. Aunque la independencia se consolidó más de tres años después, fue en torno a esta fecha -28 de julio de 1821 - en que se empezó a construir un nuevo imaginario nacional e historiográfico desde el propio siglo XIX.

Camino a las celebraciones por el bicentenario de la independencia, en el Perú se lleva tiempo repensando - sobre todo en ámbitos académicos- el discurso nacional sobre la independencia peruana ${ }^{5}$. Frente a la inquietud sobre qué celebraremos cuando celebremos el bicentenario, surgen varias interro-

2 Enríquez, 2018: 81-112.

${ }^{3}$ La respuesta de los vecinos limeños estuvo condicionada por las circunstancias. Aunque hubo una facción patriota — que aún está pendiente de profundo estudio - en contacto y coordinación con José de San Martín antes de su desembarco en Perú e ingreso a Lima, la bibliografía da cuenta de que, luego de la salida del virrey La Serna a la sierra, se produjo una situación caótica. Fue entonces cuando fue llamado San Martín a entrar en la capital para pacificarla. Así, las elites limeñas se sintieron presionadas en el momento de proclamarse la independencia. San Martín, más que el libertador del Perú, fue el salvador de Lima. Sánchez, 2001: 252. Anna, 2003: 237.

${ }^{4}$ Ortemberg, 2014: 229-248.

${ }_{5}^{5}$ Por poner algunos ejemplos, tenemos el congreso nacional organizado por la Academia Nacional de la Historia del Perú (2005) y la posterior publicación de las actas. En esta misma línea, aunque centrado específicamente en la independencia, el coloquio internacional llevado a cabo el 2014: «Las independencias antes de la independencia», organizado por el Instituto Francés de Estudios Andinos, el Instituto de Estudios Peruanos y la Pontificia Universidad Católica del Perú. Este coloquio fue precedido por un concurso nacional: "Narra la independencia desde tu pueblo, tu provincia o tu ciudad", con la expectativa de dar voz no necesariamente a los académicos, sino sobre todo a los estudiosos y especialistas locales. Un texto que recoge un importante conjunto de artículos sobre la independencia vista desde las regiones es Chust y Rosas, 2017. 
gantes $^{6}$, siendo una de las más fuertes y contundentes la que se refiere al papel de las regiones en el proceso de independencia. El Proyecto Especial Bicentenario de la Presidencia de Consejo de Ministros, por ejemplo, viene realizando actividades descentralizadas en distintas ciudades del Perú en el intento de incorporar las historias locales a las conmemoraciones nacionales ${ }^{7}$. No obstante, el reto de la Academia sigue siendo redescubrir los procesos de independencia regionales e insertarlos en un nuevo discurso histórico y político. Si bien la proclamación de la independencia en Lima constituyó un antes y un después en la historia de la independencia del Perú, no resume la realidad nacional de un virreinato conformado por extensas regiones con vida propia, con mecanismos económicos interdependientes pero hasta cierto punto autosuficientes, que antes del 28 de julio de 1821, ya habían proclamado la independencia, ya habían iniciado un gobierno independiente y una historia en paralelo a la capital virreinal. En esta línea, la primera gran extensión territorial que proclamó la independencia fue el norte del Perú, esto es, la intendencia de Trujillo ${ }^{8}$.

Gobernada por el limeño José Bernardo de Tagle, la intendencia de Trujillo estaba conformada por partidos importantes como Piura, Lambayeque, Cajamarca, Chachapoyas, Chota, Huamachuco, Pataz y Trujillo capital'. Su

${ }^{6}$ ¿Celebramos el inicio de una vida independiente? Si es así, ¿desde cuándo somos realmente independientes y respecto a qué? ¿Se celebra la independencia del Perú entendido como una nación? ¿Se celebra la independencia a pesar de que para 1821 aún no éramos del todo independientes? ¿El fin de un proceso? ¿Realmente el proceso de independencia terminó en la década de 1820 ?

${ }^{7}$ Las actividades más recientes y de mayor impacto en investigación y debate son: el Congreso Internacional Entre el Océano Pacífico y los Andes: La expedición libertadora en perspectiva histórica 1820-2020, Lima, noviembre de 2019; y la primera edición de la Cátedra Bicentenario, realizada el 22 de julio de 2020 en modalidad virtual. En esta cátedra participaron cuatro historiadores: Manuel Chust, Silvia Escanilla, Gabriela Chiaramonti y Elizabeth Hernández.

${ }^{8}$ La primera ciudad-puerto en proclamar la independencia en el Perú fue Supe, al norte de Lima, el 5 de abril de 1819, aprovechando la invasión que sufrió por parte de la escuadra libertadora al mando de Lord Cochrane. Le siguió la ciudad de Ica en octubre de 1820. Respecto a esta, aunque la Comisión Nacional del Sesquicentenario de la Independencia del Perú, fijó el 21 de octubre de 1820 como fecha de proclamación de la independencia en Ica, parte de la documentación da a entender que esta se realizó antes del 20 de octubre de 1820. Antología de la Independencia del Perú, 1972: 371.

9 Artículos que trabajan comparativamente algunos aspectos de la región norte en la colonia y en la independencia: Aldana, 2020: 27-86. Flores Guzmán, 2011: 39-86. Sánchez, 2011: 129-171. O’Phelan, 2019: 389-437. 
influencia se extendía hasta Maynas —en la selva norte del Perú- y Jaén ${ }^{10}$. Este norte peruano era una región de gran vitalidad económica, con haciendas de caña, arroz, algodón, con minas, obrajes, tinas de jabón, y con un gran comercio dentro y fuera del virreinato del Perú, siendo puertos de destino frecuentes Guayaquil, Panamá, Jamaica, Lima y Valparaíso. Se trataba de una sociedad regional económicamente pujante ${ }^{11}$, con una elite que destacaba en el conjunto virreinal ${ }^{12}$ y por ende con muchos intereses que resguardar y mantener. En este espacio, algunas proclamaciones de independencia fueron circunstanciales, pero lo cierto es que en el norte se vislumbra actividad anterior a la llegada de José de San Martín a las costas peruanas, la cual no ha estado necesariamente contemplada en la historiografía.

La historia del norte en el proceso de independencia está aún por hacer. Existen trabajos que centran el interés en las localidades o partidos que formaban parte de la intendencia de Trujillo, pero se echa en falta una visión analítica de conjunto que nos permita ver la actuación de los distintos actores sociales, políticos y económicos, así como las redes de contacto y de poder que fueron el soporte en la decisión final de personas e instituciones por la causa patriota. En las páginas que siguen ofrecemos un primer esbozo en el que se trata de mostrar la complejidad del proceso de independencia de esta región, los niveles en los que se tiene que analizar el espacio norte en esta coyuntura y las fases en que se fueron desenvolviendo las acciones en los primeros años del Perú independiente.

\section{REAFIRMACIÓN LOCAL E INTERESES PARTICULARES EN CONFLICTO}

No queda claro en qué momento el norte peruano fue construyendo un discurso político local o regional. Lo que se advierte para fines del siglo XVIII es la afirmación de la ciudad, del pueblo o de la vecindad a través, sobre todo, del frente económico y de la búsqueda de beneficios para los propios lugareños. Se aprecia en la documentación un discurso político local propio, una

${ }^{10}$ En efecto, durante el proceso de independencia y, sobre todo, en la conformación del primer congreso constituyente del Perú independiente los diputados de Jaén y Maynas llegaron al congreso integrando la representación departamental de «La Libertad», nuevo nombre que se otorgó a la intendencia de Trujillo en reconocimiento de los servicios prestados a la causa de la independencia. Gerberging, 1953: 4.

11 Sobre la economía del norte peruano ver: Contreras Carranza y Hernández García, 2017. Reyes Flores, 1999. 2008 .

${ }^{12}$ Véase al respecto: Rizo-Patrón y Aljovín de Losada, 1998: 241-293. Hernández García, 
conciencia de pertenencia a un espacio, lo que da una idea de primacía que se quiere se respete. La preferencia por los patricios beneméritos del lugar fue un tema recurrente en las solicitudes cursadas para la consecución de un nombramiento civil o eclesiástico. En este ámbito, y a finales del siglo XVIII, la principal preocupación de los norteños era la primera opción que siempre tenían los miembros de las elites más poderosas sobre sus relaciones de méritos. El cerrado círculo del cabildo catedralicio trujillano es el mejor ejemplo $^{13}$. Silvestre de Carrión, presbítero piurano que en 1795 aspiraba a una canonjía, protestó porque la terna la encabezaba, no solo alguien que era sobrino del obispo, sino que además no formaba parte del obispado trujillano, era un recién llegado:

... se me ha postergado, sufragándome únicamente el segundo lugar en concurrencia de unos sujetos que además de ser extraños en su origen de este obispado (calidad que tan repetidas veces tiene recomendada V.M. por distintas cédulas para la atención de los patricios beneméritos) no pueden igualar a mis servicios ni a las funciones literarias que tengo acreditadas a satisfacción de todo el público... ${ }^{14}$

Silvestre de Carrión deja claro con estas expresiones la existencia de un círculo de redes y contactos donde la oriundez importaba mucho, así como el que los cargos de más peso en el obispado, se pensaba, debían recaer en vecinos o avecindados. El caso de Silvestre Carrión es complejo porque evidencia todo un entramado de grupos de poder eclesiástico que en el fondo son grupos de poder local, que se ayudan recíprocamente, y que se movilizan en la defensa de sus «derechos» o prerrogativas violentadas desde fuera de su entorno o de su localidad. Se está poniendo de manifiesto, además, una visión provincial en estos grupos de poder. Como veremos más adelante, aquella se hará presente en el propio proceso de independencia.

El mismo argumento utilizado por Silvestre es traído a colación años después por su sobrino, el también piurano Francisco de Carrión e Iglesia, en la oposición a una canonjía doctoral en Trujillo el año 1809:

La calidad de originario de esta diócesis, y descendiente de las más ilustres y antiguas familias, es otro fundamento que vigoriza mi alegato. No hay proposición más cierta y apoyada en todos los derechos, como la que establece la prelación de los beneficios, prebendas y dignidades entre los naturales respecto de los extraños, $y$ de los hijos de los progenitores beneméritos en concurso de los que no lo son ${ }^{15}$.

\footnotetext{
13 Véase al respecto, Hernández García, 2006: 15-45.

${ }_{14}$ Archivo General de Indias, Sevilla (AGI), Lima, 1583, año 1795, fol. 11. La cursiva es nuestra.

15 AGI, Lima, 1589, año 1809, fol. 5. La cursiva es nuestra.
} 
Carrión fue mucho más allá de un simple enunciado, o del recuerdo de pragmáticas en esta línea. Él sentenció que la preferencia de los patricios del lugar era de orden divino:

Sería trabajo ímprobo y superfluo, aglomerar todos los textos de Derecho Divino, Eclesiástico, Real de España y Municipal de Indias, que protegen este punto, cuando V.S. sabe bien que el mismo Dios confirma la preferencia del patricio, aun para los más sagrados empleos, y que ésta la observan todas las provincias y reinos que conocen por universal madre a la Iglesia Romana... ${ }^{16}$

Y finalmente sustentaba:

... y que al fin es derecho natural que no sean repelidos para los cargos y empleos temporales, y espirituales de su patria aquellos que nacieron en ella, que la sirven, ayudan y defienden ${ }^{17}$.

Ambas protestas en el mismo escenario del cabildo catedralicio trujillano, con la diferencia de los protagonistas y del lustro en que se dieron, amén del gran interés en formar parte del alto clero, dan cuenta de un sentimiento de identificación con un grupo y con un espacio concretos, algo en lo que tiene mucho que ver la cercanía geográfica, las relaciones de parentesco, los vínculos sociales, económicos y culturales, los cuales se agudizarían o se fraccionarían, posiblemente, en círculos más reducidos durante eventos de crisis política posteriores como fueron los del proceso de independencia.

Respecto a esto último, en el período de las cortes de Cádiz, podría decirse que volvió a hacerse elocuente similar discurso. A través de sus diputados en la península, las distintas vecindades buscaron reafirmar privilegios, potenciar la economía, solicitar gracias especiales, algunas veces argumentaron tener títulos de nobleza distintos a los estrictamente nobiliarios. Una ciudad representativa a este respecto fue Piura. La vecindad piurana se consideraba la primera en servir al rey al haber sido la primera fundada por españoles en el Perú. Siguiendo esta línea, el cabildo de Piura era el más antiguo del Perú, una connotación de elite que la superponía sobre otras vecindades en el virreinato del Perú. En las Instrucciones que le fueron dadas al diputado en Cortes por Piura, José Antonio Sánchez Navarrete, el cabildo le decía que debía procurar «la conservación de sus fueros, honras, mercedes y franquicias, gracias y propios que ha merecido por su lealtad, antigüedad y servicios des-

\footnotetext{
${ }^{16}$ Idem. La cursiva es nuestra.

17 Ibidem, fol. $5 \mathrm{v}$. La cursiva es nuestra.
} 
de su fundación». Es decir, en España, el diputado piurano sería el encargado de recordar los méritos del cabildo ${ }^{18}$, de la pequeña vecindad ${ }^{19}$.

Fue un lugar común el que los diputados que viajaron para estar presentes en Cádiz argumentaran en favor de sus localidades. Aun cuando el período gaditano había llegado a su fin, algunos siguieron insistiendo en la búsqueda de beneficios para sus ciudades. El presbítero Gregorio Guinea, quien llegó a ser deán de la catedral de Trujillo y ex diputado a cortes ordinarias por esta ciudad, solicitó la construcción de dos fortalezas, cada una con ocho cañones, en los puertos trujillanos de Huanchaco y La Garita, puesto que eso solucionaría el gran problema de inseguridad que vivía el comercio trujillano que se hallaba a merced de los ataques enemigos en tiempos de guerra, habida cuenta de que Trujillo, siendo tan importante, no contaba con fortaleza alguna ${ }^{20}$.

La protección del comercio era esencial, pues se constituía en el soporte de la economía de todo el espacio. En este período gaditano podemos apreciar que las miradas eran locales, muy de defensa de los fueros citadinos, de preservación de prerrogativas de antaño en relación con la ciudad de la cual se era vecino ${ }^{21}$. Esta cuestión es muy importante, pues caracterizó también la década siguiente y también el inicio de la república. Si bien existía el norte como espacio físico distante y distinto del centro administrativo de poder político, el funcionamiento en muchos órdenes fue esencialmente fragmentario. Eso explica el hecho de que, en plena guerra por la independencia, las proclamaciones a favor de la causa patriota no tengan que ver con una entidad en bloque que se moviliza o con unas expectativas en común, sino con ciudades en concreto cuyas clases dirigentes decidieron apostar por otra opción política, manteniendo el statu quo, salvaguardando sus vidas y sus bienes o arriesgándolo todo en el convencimiento de que el gobierno independiente era su mejor decisión. En realidad, el norte era un espacio regional fragmentado y como tal se comportó pocos años después.

Durante el período gaditano, el norte peruano en su conjunto mantuvo su adhesión a la figura del rey Fernando VII. No hubo revoluciones contrarias al régimen ni tampoco algún intento, como sí se dio en otros puntos del vi-

18 Hernández García, 2008: 208.

19 Si bien estas Instrucciones entregadas a los diputados peruanos tenían un tenor similar, son evidencia del interés de la localidad en aprovechar la oportunidad que se les brindaba de presentar sus demandas en la propia metrópoli a través de representantes directos.

20 AGI, Lima, 981/1798-1818/expedientes pendientes de informe, fol. 8.

${ }^{21}$ Sobre la distribución regional de los diputados representantes del Perú en Cádiz: RizoPatrón y Salinas Pérez, 2014: 53-81. 
rreinato, de conformar una junta de gobierno ${ }^{22}$. Antes bien, hubo mucha inquietud cuando se tuvo noticia de la revolución en Quito en 1809. La movilización de las elites que tenían frontera con el actual Ecuador fue de reafirmación de la fidelidad al gobierno del virrey Abascal y al que se ejercía desde la metrópoli. Cuando se tuvo referencia cierta del levantamiento quiteño, el cabildo de Piura se puso en movimiento para impedir una invasión y custodiar la ciudad; se buscó asesoría en el presbítero Francisco de Carrión e Iglesia para elaborar un plan de defensa. Y finalmente, cuando el peligro pasó, los miembros del municipio agradecían a este clérigo porque gracias a él se había podido asegurar la tranquilidad de la provincia. Al año siguiente, en 1810, se mantenía la zozobra sobre Quito; de nuevo la respuesta de las elites piuranas, cercanas geográficamente a aquella ciudad ecuatoriana, fue proponer algunos medios para estar prevenidos ${ }^{23}$. Lo cierto es que el espacio conformado por la intendencia de Trujillo era uno de los bastiones de gran fortaleza con que contaba el virreinato del Perú y el virrey Fernando de Abascal. Esta circunstancia cambió significativamente en menos de una década.

Para el caso del norte peruano hubo variadas circunstancias históricas, sobre todo durante el retorno al absolutismo monárquico, que incidieron en el giro hacia la opción que representaba José de San Martín. Entre los hechos que tuvieron impacto en el espacio norte del Perú destaca la proclamación de la independencia del Río de la Plata en $1816^{24}$. Este hecho afectó al sector de privilegio, siendo lo más significativo el peligro que representaron los ataques de Guillermo Brown en las costas peruanas. Al servicio de la escuadra rioplatense, Brown llegó a aguas del Pacífico Sur y atacó varios puertos. En febrero de 1816, el comandante general del puerto de Guayaquil escribía al virrey Pezuela notificando la presencia de 14 buques enemigos en las costas de Tumbes. El virrey lo comunicó a las autoridades de Trujillo, Paita y otros puertos norteños ${ }^{25}$. Según Miguel Seminario, «la escuadra de Brown aparecía y desaparecía ${ }^{26}$, manteniendo en ascuas las actividades mercantiles durante

22 Temple, 1971: 16. O’Phelan Godoy, 2016b: 297-310. Hernández García, 2016: 315337. Pereyra Chávez, 2016: 339-361. Rojas Porras, 2016: 363-384. Buller, 2016: 385-408. Lanas Castillo, 2016: 409-433. Rizo-Patrón Boylan, 2016: 435-456. Aunque no hubo un intento de movimiento juntista en el norte, sí hubo simpatías de algunos norteños con la primera y la segunda junta quiteña. Un ejemplo fue el caso del clérigo piurano José Antonio Mena, descrito como «insurgente seductor». O’Phelan, 2014: 63.

${ }^{23}$ Hernández García, 2008: 215.

24 Decisión tomada por el Congreso de Tucumán el 9 de julio de 1816.

${ }^{25}$ Archivo General de la Nación, Lima (AGN), GO-CO, caja 212, cuaderno 3646, año 1816. fol. 2.

${ }^{26}$ Seminario Ojeda, 1994: 41-42. 
algunos meses. De otro lado, el 22 de septiembre de 1817 se produjo la captura del Abascal, pailebote correo de S.M., en el puerto de Paita por una flota de «insurgentes»; no se precisó quién los comandaba.

Quedaba claro que los patriotas estaban cerca y podían accionar en un puerto de gran importancia en el comercio y en las comunicaciones virreina$\operatorname{les}^{27}$. A partir de ese momento, los ataques se sucedieron en distintos puntos de América Hispana, y las noticias fueron llegando al puerto de Paita, contribuyendo a la incertidumbre. El Diario de Pezuela, el 28 de febrero de 1818, daba cuenta de que el comandante de Paita le avisó haber llegado a Guayaquil cuatro ingleses de veinte que los corsarios echaron en la costa de Montecristo (El Salvador), procedentes de una fragata ballenera que echaron a pique para obligar a su tripulación a tomar partido con ellos ${ }^{28}$. Para 1818 , la causa patriota había triunfado en Chile, hecho que agudizó la sensación de inquietud y la crisis económica que se estaba viviendo en algunos espacios del virreinato peruano, sobre todo en la capital ${ }^{29}$.

Otra circunstancia que impactó en el espacio norte fue la llegada de la escuadra patriota al mando de Lord Cochrane, escuadra que en 1819 desembarcó en distintos puertos peruanos originando reacciones diversas. El punto de quiebre para el norte lo representó la incursión de este marino inglés a Paita. Los informes oficiales indican que la escuadra de Cochrane asoló Paita, hubo expolio y destrucción. El mismo Cochrane, cuando se enteró de las acciones realizadas por la marinería sobre todo en el despojo de algunas iglesias, sancionó duramente a los culpables intentando recuperar en parte la opinión pública ${ }^{30}$.

Esta incursión originó dos procesos opuestos. Por un lado, acostumbrados los paiteños al ataque de piratas y corsarios, la elite cuestionó la causa patriota en virtud de estos desmanes, llegando a catalogar a la escuadra como «los piratas de Chile», y acusaron que esta actitud también se había dado en otros puertos $^{31}$. Así que, para una parte de la población, la escuadra libertadora fue vista como enemiga. Y por otro lado, la población indígena paiteña recibió a

27 El gobierno consiguió reemplazar el Abascal por el Guadalupe; no obstante este último siguió la misma suerte que el primero en la incursión que hizo Lord Cochrane al puerto de Paita dos años después. AGI, Correos 114 A, Ramo 1, n. ${ }^{\circ}$ 2, 1819.

${ }^{28}$ Rodríguez Casado y Lohmann Villena, 1947: 237.

29 Sánchez, 2001. Anna, 2003.

${ }^{30}$ Hernández García, en prensa.

31 Nos referimos a Huacho, Supe y Huarmey. En estos puertos, afirma la documentación patriota, los lugareños ayudaron a los marineros a buscar bienes en las casas de las familias principales. Pons Muzzo, 1971: 133, 591. Sobre el pirata como extraño y extranjero, ver: Flores Guzmán, 2005: 33-50. 
la escuadra patriota con gran júbilo y algarabía. Inclusive, reunidos en común, prometieron a Cochrane que, si les dejaba armas, defenderían aquel puerto como suyo y de los insurgentes ${ }^{32}$. Ambas reacciones son comprensibles dentro de una sociedad estamental como la virreinal, y reafirman la idea de que no hay una única lectura en el estudio de la independencia cuando de grupos sociales hablamos.

Para el ámbito del norte, y desde la perspectiva de la elite, quedaba clara la situación de «peligro» que suponía la causa de la patria, aunque no descartamos algunas simpatías también, habida cuenta de que, para ese momento, José de San Martín venía enviando comunicaciones a distintos personajes de la sociedad peruana tratando de convencerles de su proyecto de independencia del Perú ${ }^{33}$. Es posible que todas estas circunstancias influyeran como condicionantes para que los distintos partidos que conformaban la intendencia de Trujillo fueran proclamando sus respectivas independencias. También en esta parte de la historia regional hay varias miradas.

\section{Las proclamaciones de independencia en el norte del Perú}

El norte peruano proclamó su independencia entre 1820 y 1821 , constituyéndose, como decíamos, en el primer gran espacio en el Perú en abrazar la causa patriota. Las razones de este cambio de opción política no son claras y caen en la esfera de hipótesis que, para el ámbito peruano e hispanoamericano, llevaron a debates historiográficos de los cuales se siguen escribiendo páginas ${ }^{34}$. Parte de la documentación de esta época tampoco ayuda a dilucidar el tema del porqué de la independencia norteña, en tanto que algunas relaciones se escribieron tiempo después de los acontecimientos en un claro intento por afirmar una adhesión temprana a la causa de la patria, que era la que gobernaba y otorgaba concesiones y beneficios ${ }^{35}$. No obstante, estos y otros documentos nos permiten desentrañar algunos elementos de

${ }^{32}$ AGI, Correos 114 A, Ramo 2. n. ${ }^{\circ}$ 5, año 1819.

33 También lo intentó hacer Cochrane con las proclamas que hacía leer en los distintos puertos en los que desembarcó.

${ }^{34}$ En la explicación de estas escuelas historiográficas sobre las independencias americanas, destaca el texto de Quijada, 2005. Un trabajo que sentó un gran precedente en los estudios históricos sobre la independencia del Perú: Bonilla, Chaunu y Halperin, 1972. Una mirada panorámica de los modelos interpretativos para el caso de la independencia del Perú la tenemos en: Contreras y Glave, 2017.

35 Es el caso, por ejemplo, del “Informe que Don José Ignacio...”, 1927. 
análisis para intentar comprender el proceso en los distintos niveles en que se pudo desarrollar.

Como decíamos líneas antes, las proclamaciones de independencia en el norte no siguieron un plan común en todo el espacio en su conjunto. Fueron proclamaciones que no obedecieron a una decisión consensuada entre todas las ciudades por un mismo motivo. El caso más emblemático lo constituye Lambayeque. Esta ciudad revestía mucha importancia en el comercio dentro de la intendencia de Trujillo y tiene mucho interés en el estudio de la independencia regional. Quien es considerado uno de los motores del movimiento independentista en esta ciudad es Juan Manuel de Iturregui. Comerciante criollo, de padre peninsular y madre lambayecana, fue uno de los fundadores de la logia «White Star», donde clandestinamente se reunían quienes eran afines a las ideas liberales y separatistas ${ }^{36}$. Según Ricardo Miranda, las ramificaciones de la logia promovida por los hermanos Iturregui se extendían a Trujillo y a Piura. Con motivo de negocios familiares, Juan Manuel Iturregui viajó a Jamaica. Ahí tuvo contacto, supuestamente, con patriotas que preparaban las expediciones a Venezuela y a Colombia, y compró armas y municiones que trajo de contrabando a Lambayeque ${ }^{37}$. Desde Lambayeque se pensaba extender el movimiento al resto de la intendencia de Trujillo, pero esto no se llevó a cabo «por las noticias adversas llegadas de Piura respecto a la guarnición que allí existía ${ }^{38}$. Según afirma el propio Juan Manuel, de todos estos movimientos tenía conocimiento José de San Martín desde antes de zarpar de Valparaíso rumbo al Perú. Se puso en contacto con la logia haciéndoles prevenciones para que efectuaran un pronunciamiento y depusieran a las autoridades españolas. Fue este club secreto el que estuvo tras la proclamación de la independencia de Lambayeque ${ }^{39}$.

Al respecto, hay que hacer algunas acotaciones más en el análisis. Tanto la historiografía como la documentación consultada afirman que la de Lambayeque fue la primera proclamación que se llevó a cabo dentro de la intendencia el 27 de noviembre de 1820, antes que se diera la de la propia capital de esta región. En segundo lugar, esta fue la denominada "primera» proclamación de la independencia de Lambayeque, la cual se realizó de manera privada, a las 10 de la noche, en reunión de 11 personas, entre los que estaban los miembros del cabildo. La razón del carácter de esta reunión, explica el acta, fue el «continuo espionaje y las trabas que por ser español europeo el

${ }^{36}$ Una breve reseña biográfica de Juan Manuel de Iturregui la tenemos en: http://www.congreso.gob.pe/Docs/participacion/museo/congreso/files/files/juan_iturregui.pdf

${ }^{37}$ Miranda, 1927: 32.

${ }^{38}$ Centurión Vallejo, 1962: 89.

39 “Informe del caudillo de la independencia. Iturregui”, en Miranda, 1927: 41. 
subdelegado presidente, podría oponer a las miras beneficiosas de esta corporación si se reuniese en la sala consistorial». Pero, creemos, tuvo más que ver con la situación en que se encontraba la ciudad aquel 27 de diciembre, pues mucha gente se había congregado en la plaza principal, intimando la rendición al jefe del escuadrón de dragones y esperando que este se encaminara hacia Trujillo $\mathrm{o}^{40}$ para que dejaran libre la ciudad. Paralelamente a este movimiento de la población, se dio la reunión privada que comentamos, posiblemente por el temor a unas masas que se podían descontrolar ${ }^{41}$.

El 31 de diciembre de 1820 se dio la segunda proclamación de la independencia de Lambayeque, la que esta vez contó además con la presencia del subdelegado, José Díaz de Arellano, de la tropa y del pueblo. Aquel día ratificaron la proclamación y juramento del 27 . No obstante, un dato más requiere mayor atención en la línea que antes comentábamos. Guillermo Figueroa da cuenta de un "Acta del pueblo medio y bajo", que fue elaborada en virtud de una movilización de «alcaldes indios» y de la «plebe» que argumentaron que el cabildo los había excluido de la proclamación del 27 de diciembre. El documento fue firmado por 64 personas, entre los que había «cuatro alcaldes indios, 57 miembros de la plebe y numerosos indios del común $»^{42}$. Como era de esperarse, no hubo mayor repercusión de este hecho en el documento que el cabildo redactó el 31 de diciembre, con la sola acotación: y de la interrupción que ocasionó uno que otro vecino que se introdujo en esta sala» ${ }^{43}$.

En Cajamarca pasó algo similar. Waldemar Espinoza afirma que el gobernador del partido, el chachapoyano Antonio Rodríguez de Mendoza, convocó a los vecinos y al cabildo de españoles para que se proclame la independencia. La elite indígena no fue convocada. Así que Manuel Soto Astopilco, cacique principal de las Siete Huarangas, y otros nobles indios, se hicieron presentes el 8 de enero de 1821 en la reunión prevista para que se proclame la independencia. Astopilco afirmó ser descendiente de Atahualpa y que por ello le correspondía ocupar el gobierno. Rodríguez de Mendoza prometió que el tema sería consultado al intendente Torre Tagle, promesa ante la cual los caciques se retiraron. Pero Torre Tagle o no se enteró o no emitió ninguna respuesta. Fue esta, en palabras de Espinoza, la primera ejemplificación, por lo menos en el norte del Perú, de cómo la independencia era un movimiento eminente-

40 Miranda, 1927: 34-35.

41 Según Ricardo Miranda, «El haberse anticipado Lambayeque en su movimiento a la ciudad de Trujillo fue debido al temor de prolongar más días una situación en la que ya comenzaba a haber vacilaciones que podían hacer fracasar el plan», Miranda, 1927: 35.

42 Figueroa Luna, 2005: 30.

43 "La segunda proclamación pública", en Miranda, 1927: 37. 
mente criollo, con nulos visos de indianidad ${ }^{44}$. Ahora ya sabemos que lo acontecido en Cajamarca fue, cronológicamente, el segundo ejemplo de ese proceso criollo en las proclamaciones de las independencias norteñas, pues no contaron con la presencia de las comunidades indígenas o de los curacas, limitación que venía de tiempo atrás ${ }^{45}$.

Entre el 27 y el 31 de diciembre se había dado un acontecimiento más: la proclamación de la independencia de Trujillo el 29 de diciembre de 1820. ¿Hubo relación con la de Lambayeque? No hay claridad. Es más, en el informe (1851) que realizó Juan Manuel Iturregui sobre estos acontecimientos, deslizó la idea de que el marqués de Torre Tagle, enterado del movimiento patriota y del incendio que se avecinaba en Lambayeque, «dictó diversas providencias para ahogarla en su foco» ${ }^{46}$. Iturregui da a entender que Torre Tagle, pocos días antes de la independencia, mantenía su realismo y, antes bien, se dedicaría a atacar la insurgencia patriota con algunos dictámenes. Esto desdibujaría la — poco profundizada — imagen de líder patriota de Torre Tagle. Al respecto, Guillermo Figueroa es de la opinión de que estas líneas del informe de Iturregui son circunstanciales y discrepan de las declaraciones que sobre el mismo personaje dio en 1821. Y es que Torre Tagle, huyendo de Simón Bolívar luego del triunfo patriota en la batalla de Ayacucho, pidió refugio en el Real Felipe del Callao, que en ese entonces estaba en poder de los realistas, y murió en esa plaza (1825). Para los contemporáneos, Torre Tagle había cambiado de bando ${ }^{47}$. Así que, en 1851 el marqués era entonces un «...árbol caído, de cuya memoria se podía hacer leña, aún a costa de cambiar los testimonios» ${ }^{48}$.

${ }^{44}$ Espinoza Soriano, 2000: 181-182.

${ }^{45}$ En el período gaditano algunas comunidades llamaban la atención acerca de la manipulación que los hacendados y las autoridades criollas y peninsulares hacían de los decretos de las Cortes en materia de ayuntamientos constitucionales, tratando de evitar la formación de estas instituciones en poblaciones de indios no obstante ser clara la Constitución al respecto. Hernández García, 2017: 138.

46 "Informe del caudillo de la independencia. Iturregui", en Miranda, 1927: 41.

${ }^{47}$ El marqués de Torre Tagle fue acusado de haber intentado negociar con los realistas. Lo cierto es que lo hizo pero siguiendo órdenes de Simón Bolívar para ganar tiempo, en un momento en el que la causa patriota peligraba. A inicios de febrero de 1824, tuvo lugar un motín de la guarnición que custodiaba el Real Felipe del Callao por pagos atrasados. Los amotinados, al no ver satisfechas sus reclamaciones, entregaron el Real Felipe a los realistas. Lima, entonces, volvió a caer en poder realista desde febrero hasta diciembre de 1824. Se acusó a Torre Tagle de haber participado de este levantamiento y de haber entregado la capital del Perú al enemigo. Los documentos prueban que fue una acusación sin fundamento. Véase Escudero, 2020: 141-180.

${ }^{48}$ Figueroa Luna, 2005: 24. 
La intendencia de Trujillo estaba gobernada por Torre Tagle desde 1820, el cual había llegado al norte rechazando la intendencia de La Paz. Posiblemente, el virrey Joaquín de la Pezuela lo colocó a la cabeza de Trujillo habida cuenta de que este espacio se hallaba en aparente tranquilidad. Queda por realizar un estudio a profundidad de la vida política del marqués en cuestión y las redes que le sustentaron en sus decisiones políticas. Lo cierto es que Torre Tagle, para ese entonces, ya estaba en comunicación con José de San Martín, no quedando muy claro en qué momento y por qué motivaciones específicas decidió apostar por el bando patriota. Según Juan Manuel de Iturregui, Torre Tagle proclamó la independencia «porque vio que no le quedaba otro recurso para salvar la conflagración revolucionaria del departamento ${ }^{49}$. Según el viajero Robert Proctor, Torre Tagle había hipotecado todas sus propiedades a españoles, y fue el primero en comunicarse con San Martín como único medio para volver a ser una persona importante ${ }^{50}$. Sin embargo, también cabe la posibilidad de que se convirtiera a la causa de la patria en virtud de la información - certera o no- que circulaba y que advertía de que, en cualquier inmediato momento, además de haber «caído» algunas ciudades al norte y al sur, también caería Lima, es decir, la causa del rey. Para diciembre de 1820 se pensaba que la invasión a la capital estaba cerca. El mismo Torre Tagle lo afirma en una comunicación enviada a Maynas cuando dice:

Con fecha catorce del corriente [diciembre de 1820] me dice el Excelentísimo Señor General [cuyo cuartel general estaba en Huaura] que iba ya a aproximarse a los muros de la capital, y que su caballería se hallaba en Chancay. Así se estrechará el sitio y se entregará el Virrey a discreción, pues la absoluta escasez (de) víveres agregada a los rápidos progresos de las tropas Libertadoras ha reducido esa ciudad a la mayor consternación ${ }^{51}$.

Con estos datos fue que Torre Tagle tuvo que decidir, prácticamente, en los dos últimos meses de 1820. Según el informe que hizo el obispo de Trujillo, José Carrión y Marfil, al virrey Pezuela, consta que el 6 de diciembre de 1820 Torre Tagle convocó a una junta a celebrarse en su casa por la noche. En ella se leyeron oficios de José de San Martín, y dejaba claro Torre Tagle «su resistencia» y el problema que suponía el mal estado de la tropa. El obispo ofreció la suma de 4.000 pesos como donativo para la causa real. Añade el prelado que, indudablemente, todos los reunidos en esa junta eran afectos

\footnotetext{
49 "Informe del caudillo de la independencia. Iturregui", en Miranda, 1927: 43.

${ }^{50}$ Robert Proctor, "El Perú entre 1823 y 1824”, en Núñez, 1971: 250.

${ }^{51}$ La cursiva es nuestra. AGI, Indiferente General, 313, año 1820, fol. 1.
} 
a la causa patriota ${ }^{52}$. El obispo no estaba desencaminado en sus apreciaciones, puesto que el 2 de diciembre de 1820, Torre Tagle respondió positivamente a San Martín argumentando que, desde la época del virrey Abascal, él ya era partidario de la independencia ${ }^{53}$.

Ya claramente decidido por la causa patriota, Torre Tagle convocó a un cabildo abierto para el 24 de diciembre de 1820, en el cual se acordó proclamar la independencia de Trujillo el 29 de ese mismo mes, así como promover las proclamaciones de los demás partidos de la jurisdicción. Se decidió se redactaran pliegos de instrucciones para Tumbes, Piura, Lambayeque, Cajamarca, Huamachuco, Chota y Pataz. El 29 de diciembre, entonces, se llevó a cabo la proclamación de la independencia en la capital de la intendencia. Evidencia de que se trató de evitar una confrontación con el sistema anterior, fue el hecho de que, por especial acuerdo, se determinó que la proclamación se haga sin el menor agravio al rey y a la bandera de España, «cuyo emblema se dispuso que permaneciese al tope en el asta del cabildo, debiendo ser arriada y recogida respetuosamente instantes después de que se terminase el acto, en cuyo momento se izará la bandera del Perú libre ${ }^{54}$. Por pedido del cabildo y de todos los concurrentes, Torre Tagle permaneció como máxima autoridad de Trujillo. José de San Martín le otorgó el republicano título de marqués de Trujillo, como afirman Rizo-Patrón y Aljovín de Losada, dentro del espíritu que animó a San Martín de mantener una nobleza de nuevo cuño que sostuviese sus planes monárquicos para el Perú 55 .

Las independencias se siguieron proclamando en el resto de la intendencia trujillana, siendo algunas promovidas por la coerción, pues Torre Tagle quería a toda costa asegurar el norte como un frente patriota firme. Ello aconteció con el partido de Piura, al cual llegó, el 3 de enero de 1821, una comunicación del marqués afirmando que, de no proclamarse la independencia en ese par-

52 "Segundo escrito del obispo Carrión al virrey Joaquín de la Pezuela. Lima, 24 de enero de 1821", en Centurión Vallejo, 1962: 131. Luego, Carrión y Marfil fue apresado por orden del mismo Torre Tagle y enviado a la ciudad de Lima desde donde partió a la península.

53 «Es a mí a quien se debe la creación del regimiento de la Concordia del Perú, en que gasté más de 40 mil pesos con el designio de hacerme de una fuerza respetable para proclamar la independencia de Lima, cuyo plan se frustró por motivos que omito para no ser difuso...», "Borrador de la respuesta de Torre Tagle a San Martín", 2 de diciembre de 1820, en Ortíz de Zevallos, 1982: 34.

${ }^{54}$ Centurión Vallejo, 1962: 80.

55 Rizo-Patrón y Aljovín de Losada, 1998: 283-284. Hay que considerar, además, los vínculos de parentesco y amicales existentes entre Torre Tagle y San Martín, cuestiones que favorecieron significativamente las alianzas políticas. Más detalles sobre estos vínculos en: O’Phelan Godoy, 2001b: 398-399. 
tido, tropas armadas tomarían la ciudad vía el puerto de Paita. A pesar de la existencia, según las fuentes, de una facción de patriotas jóvenes que buscaban la separación, fue la amenaza de Torre Tagle la que movilizó al vecindario piurano, convocándose con urgencia un cabildo abierto para el día siguiente, 4 de enero de 1821, en el cual, luego de acalorados debates y de algunas intervenciones contrarias a la causa patriota ${ }^{56}$, se decidió proclamar la independencia. La presión ejercida por Torre Tagle se extendió hasta Moyobamba, capital de la comandancia general de Maynas. Al cabildo de esta ciudad Torre Tagle, en enero de 1821, le amenazó con retirarle el situado si es que no se proclamaba la independencia ${ }^{57}$.

Ese norte patriota del que se sentían orgullosos el marqués de Torre Tagle y José de San Martín tuvo su contraparte: los movimientos contrarios a la patria que, aunque locales, fueron una preocupación en medio de una guerra general que aún no se había ganado. Los realistas iniciaron una contrarrevolución en Cajamarca, esperando «sublevar los pueblos de la sierra cajamarquina y trujillana, así como de Chachapoyas, Moyobamba y Jaén, y después atacar y vencer a Torre Tagle con el objetivo de recuperar para la causa realista la intendencia de Trujillo ${ }^{58}$. De ser así, el movimiento ya no estaría focalizado en una ciudad concreta, sino que revestía mayor peligrosidad porque buscaba una proyección mayor. Se temía, además, que esta reacción tuviese ayuda de la guarnición realista y veterana de Moyobamba ${ }^{59}$. El movimiento, liderado por Mariano Castro Taboada, empezó en Otuzco en abril de 1821. Hubo dos intentos de conciliación con los contrarrevolucionarios que fueron infructuosos, así que finalmente Torre Tagle decidió combatirlos por las armas ${ }^{60}$. Ello se realizó en Otuzco, con tropas al mando de Andrés de Santa Cruz, el 6 de julio de 1821, desbaratando con esto el peligro en Cajamarca ${ }^{61}$.

Por su parte, donde más se complicó la situación fue en Maynas. El comandante general Manuel Fernández Álvarez, desoyó la intimidación que le había hecho Torre Tagle. Teniendo conocimiento de que Chachapoyas - par-

${ }^{56}$ Nos referimos a la intervención de Francisco Javier Fernández de Paredes, marqués de Salinas, quien en todo momento se manifestó contrario a declarar independiente el partido de Piura. Hernández García, 2007: 361-391.

${ }^{57}$ AGI, Indiferente General, 313, año 1820, fol. 1.

${ }^{58}$ Centurión Vallejo, 1962: 96-97, 100.

59 Rebaza, 1971: 137.

${ }^{60}$ Centurión Vallejo, 1962: 100.

${ }^{61}$ «Al final, Otuzco fue tomado a sangre y fuego por las tropas de la Patria enviadas desde Trujillo por Torre Tagle y comandadas por el coronel Santa Cruz», en Villanueva Urteaga, 1974: 21 . 
tido contiguo - había proclamado la independencia ${ }^{62}$, se retiró a La Laguna, lugar donde se llevó a cabo una reunión a la que asistió también el obispo de Maynas, Hipólito Sánchez Rangel y el coronel Tolrá. No hubo acuerdo sobre la manera en que se resistiría ${ }^{63}$. Se le dieron pasaportes a Sánchez Rangel y a su secretario, José María Padilla, quienes se refugiaron en Tabatinga, frontera con Brasil. La invasión patriota a Moyobamba, liderada por Pedro Pascasio Noriega, no tuvo éxito, pues su teniente, José Matos, se pasó al bando realista y, ayudado por esta facción moyobambina, el 10 y el 11 de abril de 1821 se enfrentó a los patriotas.

Aunque no fue un triunfo definitivo, esta noticia hizo que el gobernador Fernández Álvarez y el obispo Sánchez Rangel se encaminaran de nuevo a Moyobamba. Se dio, entonces, un segundo enfrentamiento, el 6 de junio de 1821, en la batalla de Higos Urco que fue, finalmente, un triunfo patriota. Fernández Álvarez se retiró a Pebas, mientras que el obispo Sánchez Rangel no alcanzó a volver a Moyobamba porque en el camino se le dio noticia de esta derrota realista. En junta celebrada en Pebas, Fernández Álvarez y demás autoridades decidieron abandonar la provincia. Mientras tanto en Moyobamba, representantes de esta ciudad, luego de que se les diese a conocer la noticia de la declaración de la independencia de Lima el 15 de julio de 1821, decidieron también, a nombre de todo el vecindario, jurar la independencia de Moyobamba, la cual se realizó el 19 de agosto de $1821^{64}$. Fue esta la primera proclamación y jura de la independencia en el norte del Perú que se dio luego de un enfrentamiento bélico, pues las anteriores ceremonias habían sido consecuencia de un acuerdo o de una opción voluntaria y pacífica. Poco tiempo después, desde el Putumayo, la reacción realista volvió a encenderse, siendo tomada de nuevo Moyobamba el 24 de mayo de 1822. Para poder recuperarla, se organizó la resistencia patriota con tropa venida de Trujillo y Cajamarca. Después de varios enfrentamientos en las afueras, los patriotas ingresaron triunfalmente a Moyobamba el 25 de septiembre de $1822^{65}$.

Evidencia de la conexión entre el movimiento realista de Cajamarca y de Maynas, nos la brinda Torre Tagle cuando, en carta a San Martín (28/07/1821), le dice que, de no ser por sus rápidas acciones, los cinco partidos de la sierra

${ }^{62}$ No existe el acta de proclamación de independencia de Chachapoyas. No obstante, por cotejo de informaciones de la época, se ha establecido como fecha de este acontecimiento el 14 de enero de 1821.

63 Vargas Ugarte, 1971: 145.

${ }^{64}$ Exposición económico-política documentada de los sucesos ocurridos en el gobierno eclesiástico, civil y militar de las provincias de Mainas, invadidas por los disidentes del Perú en los años de 1820 y $1821 \ldots$. AGI, Quito 274.

65 Vargas Ugarte, 1971: 148. 
se hallarían sin duda separados de la causa patriota, pues «La provincia de Maynas obstinada en oponérsenos, había combinado sus planes con la de Cajamarca para insurreccionar el territorio de mi mando ${ }^{66}$. El peligro añadido de ambas contrarrevoluciones era que buscaban o estuvieron en contacto con las fuerzas realistas del virrey José de la Serna que se encontraban en la sierra central del Perú. En relación sobre todo a Maynas, Mariano F. Paz Soldán afirmaba que terminó así «un levantamiento que si se le dejaba tomar cuerpo hubiera comprometido seriamente la seguridad de los patriotas en el Norte» ${ }^{67}$.

Las proclamaciones de independencia en el norte del Perú supusieron acuerdos, negociación, amenazas, revoluciones y contrarrevoluciones. No estamos frente a una región que en conjunto optó por la causa patriota y que, prácticamente sin fisuras, se encaminó a su vida independiente. En la mayoría de partidos de la intendencia la independencia se proclamó porque cada vez la causa patriota ganaba más terreno y, siguiendo las preocupaciones del marqués de Torre Tagle, porque el propio virrey estaría cerca de capitular. La causa de la patria jugó con los temores, la incertidumbre, el miedo a una gran persecución ${ }^{68}$ y las distancias geográficas que influyeron decisivamente en la celeridad de las ciertas o infundadas comunicaciones. Lo cierto es que, con sus bemoles, la independencia del norte se proclamó, y este espacio se constituyó en el centro del poder patriota en el Perú los primeros meses del año 1821.

\section{El norte y el Perú indePendiente}

Al ser la intendencia de Trujillo el primer gran frente que proclamó la independencia en el Perú, se convirtió de pronto en el primer gran espacio de poder del gobierno del Perú independiente. De tal manera que los partidos que dependían de esta intendencia tuvieron a Trujillo como la primera capital administrativa del Perú patriota. La autoridad máxima de toda esta región seguía siendo el marqués de Torre Tagle. De él dependieron muchas decisiones en apoyo de José de San Martín. De ahí que pueda afirmarse que el norte peruano fue un gran apoyo para el proceso de independencia peruana. La intendencia de Trujillo envió dinero, ganado, medicinas y hombres al

${ }^{66}$ Ortíz de Zevallos, 1982: 90.

${ }^{67}$ Paz Soldán, 1962: 289.

${ }^{68}$ El obispo de Trujillo, temiendo ser perseguido, pidió pasaporte, como vimos, para viajar por su diócesis. Y sus temores fueron fundados. Además, dos hermanos de quien fuera vicario eclesiástico de Piura y luego obispo de Trujillo, el trujillano Tomás Diéguez Florencia, se fueron del Perú y se asentaron en España a inicios de 1821 esperando escapar de «la patria». 
cuartel general de San Martín como refuerzos para la resistencia en el sitio que se estaba haciendo a la capital virreinal. En este particular momento volvemos a hallar divisiones entre algunos partidos de la intendencia de Trujillo en ese apoyo a la causa de la patria.

Debido a la primacía en la proclamación de la libertad, las autoridades de Lambayeque enviaron los primeros auxilios para San Martín: 300.000 pesos en metálico y 200.000 por valor de vituallas, telas y cordobanes, alhajas de los templos lambayecanos, vestuario, armas y considerable ganado. Se dio luego una convocatoria general para tomar las armas en defensa de la patria. Se organizaron tropas con un efectivo de 800 hombres. Esta fuerza marchó al sur conducida por Iturregui y Saco. Se cuenta que San Martín, al pasarle revista, dijo: «Con estos hombres y estos auxilios se hará la independencia del Perú» ${ }^{69}$. Los lambayecanos, entonces, se encaminaron hacia Huaura a afirmar tanto su compromiso como a sentar precedente del apoyo que esa localidad podría brindar, tal vez con miras a la consecución de algunos beneficios. Los lambayecanos se colocaban al lado del hombre poderoso del momento.

En octubre de 1821, los vecinos y apoderados de los comerciantes de Lambayeque hicieron sentir su voz de protesta al solicitar al gobierno de Lima se revise la nueva disposición que habilitaba los puertos menores de Paita, Huacho y Pisco para el transporte de los frutos territoriales; esta disposición cerraba, además, para el mismo fin los puertos de Pacasmayo y rada de la boca del río Lambayeque. Los comerciantes lambayecanos afirmaban que esto era un despropósito, puesto que Pacasmayo era el puerto más importante de ese espacio y era la provincia

... más mercantil de toda la costa... [la que se comunicaba] con Guayaquil y Panamá, a cuyas plazas remite azúcar, cajas de dulce, colchas, sombreros y petates de paja, y hasta las uvas de que carecen los guayaquileños... A Lima [Pacasmayo] provee de arroz, jabón, cordobanes y algunas manufacturas de algodón y paja, retornando de la costa del norte cacao, madera, pitas, cera, cocos y los demás frutos de aquellos países ${ }^{70}$.

Los comerciantes norteños pedían se habilite también Pacasmayo y otros puertos cercanos al río Lambayeque, es decir, que se elimine la disposición que los perjudicaba. Pacasmayo era un puerto importante en el circuito mercantil en aquel espacio y con ramificaciones hacia el norte, el sur y dentro y fuera del Perú, como bien lo recuerdan sus mercaderes. El superior gobierno solicitó la opinión al respecto inclusive del tribunal del consulado de Lima,

\footnotetext{
${ }^{69}$ Miranda, 1927: 35.

70 AGN, Superior Gobierno, leg. 38, cuaderno 1368, año 1821, fol. 1.
} 
la cual fue negativa. Interesa destacar la respuesta de Trujillo a este expediente ${ }^{71}$ promovido por los vecinos y comerciantes lambayecanos, ya que explícitamente se reconoce que Lambayeque había jurado la independencia antes que la capital de la intendencia: «pues si Lambayeque juró la suya un día antes que la Capital [Trujillo], sabido es que no lo habría hecho a no estar cierto de lo que al día siguiente había de hacerse en Trujillo, cuyos sentimientos, así como las disposiciones de su gobierno eran bien notorios» ${ }^{72}$. Al final, el pedido de Lambayeque no fue tomado en cuenta. Pero lo que interesa aquí es el elemento político que los lambayecanos introducen y que los superponía a las demás ciudades norteñas: haber sido la primera ciudad en contribuir a la causa de la patria, días antes de que Trujillo proclame su independencia. Vale la pena por lo menos advertir la existencia de estas «fracturas», divisiones, intereses locales que condicionarían una crisis de autoridad en este espacio con relación, tanto a los nuevos centros de poder y autoridades, como a las determinaciones que aquellos establezcan ${ }^{73}$.

Trujillo en bloque, por las coordinaciones que realizaba Torre Tagle, fue en esos primeros meses el lugar desde donde se agenció de recursos el libertador. Constantemente, San Martín escribía a Torre Tagle pidiendo auxilios de todo tipo. El marqués remitió más de 2.000 reclutas, permitiendo a San Martín proseguir con sus planes militares. Dicho contingente resultó conveniente, pues a pesar de las diarias deserciones en la capital, estas no alcanzaban a reemplazar el número de bajas causadas por la epidemia que sufría el ejército patriota en Huaura ${ }^{74}$.

Desde el momento en el que la intendencia trujillana se hizo patriota, se advirtieron problemas entre los partidos que la conformaban. Para los norteños, Trujillo fue la primera capital del Perú independiente, dependían de sus decisiones. Esto no gustó mucho en espacios que, desde la década anterior, tenían un discurso político de reafirmación local muy fuerte. Así que en este primer momento se dieron los primeros enfrentamientos. El partido de Piura se enfrentó dos veces a las directrices de Torre Tagle cuando este quiso imponer nuevas autoridades políticas y militares allí. La vecindad piurana rechazó a Carlos Ortega, nombrado gobernador y comandante militar de Piura por

71 Este documento, fechado el 26 de noviembre de 1821, probaría que las autoridades de Trujillo reconocían en aquel año que la independencia de Lambayeque se había proclamado antes que la de la capital de la intendencia norteña, aunque esta primera proclamación de independencia lambayecana haya sido, como señala la historiografía regional, a puerta cerrada.

72 AGN, Superior Gobierno, leg. 38, cuaderno 1368, año 1821, fol. 5.

${ }^{73}$ Hernández García, 2012: 122.

74 Sánchez, 2001: 245. 
Torre Tagle. Un cabildo abierto acordó no recibirle y solicitar a Trujillo que en su lugar fuera nombrado Manuel Diéguez Florencia, trujillano avecindado en Piura desde fines del siglo XVIII, y casado en 1806 con la piurana María Ventura de la Cotera ${ }^{75}$.

El apellido Diéguez formaba parte de la sociedad piurana y de las redes de contacto de las elites de aquella localidad. Así que en el rechazo de la vecindad piurana a Ortega se pueden advertir temas tan sensibles como la ratificación de la autonomía y del poder de decisión y gobierno de los cabildos locales — cosas que habían podido hacer antes de la independencia-, la idea antes mencionada de que ningún extraño al lugar obtuviera los mayores sitiales, y la búsqueda de beneficios para los miembros de la propia vecindad. Torre Tagle accedió, pero pronto tuvo que poner mano dura a los requerimientos desde Piura, pues cuando luego colocó al argentino Félix Olazábal como comandante militar de aquel partido, la vecindad piurana volvió a manifestarse en contra. Esta vez, Torre Tagle amenazó con la invasión militar si es que no se acataban sus disposiciones ${ }^{76}$.

Tal vez el temor de los vecinos piuranos era la imagen de arbitrariedad y despotismo que suponía un gobierno sin relación con los locales. En octubre de 1822, desde Sechura, un amigo se comunicaba con el entonces vicario eclesiástico de Piura, Tomás Diéguez Florencia, para comentarle la situación de la provincia gobernada por extranjeros:

Piura y su provincia consternada se queja amargamente con los señores porteños que la han mandado, porque en ellos se les ha presentado un tirano, déspota que la ha subyugado, como bien claro se manifiestan con Olazábal, Villa y Rojas, los tres enemigos del alma. No hay uno que no esté temeroso con sus providencias... y así es que no hay uno que viva tranquilo ${ }^{77}$.

Es probable que este tipo de opiniones sobre el gobierno de las autoridades foráneas e impuestas se acerque a lo que de verdad pasaba. Pero lo importante, además de la situación de descontento, es que todo ese conjunto de acciones fomentaría una mirada de recelo hacia las disposiciones venidas de fuera del espacio local y regional: hacia Trujillo primero y Lima después ${ }^{78}$. Ello

${ }^{75}$ Archivo Regional de Piura, Piura (ARP), Libro de Casamientos, n. ${ }^{\circ}$ 5, años 1802-1837, folios $13 \mathrm{v}-14$. Un hermano de Manuel, Nicolás, contrajo matrimonio con otra piurana, Josefa López Merino.

${ }^{76}$ Hernández García, 2017: 141. Podría afirmarse como hipótesis que la imposición de autoridades de fuera del Perú en Piura — como fue el caso de Olazábal— estuvo vinculada sobre todo a la voluntad de José de San Martín.

77 AGN, Colección Tomás Diéguez (CTD), carpeta 8, caja 8, año 1822, fol. 1v-2.

${ }^{78}$ Es posible, además, que estas acciones fomentaran la xenofobia de que se quejaba amargamente Simón Bolívar a partir del año 1823. Este rechazo al elemento extranjero fue 
explica, por ejemplo, el visceral pedido que le hace un comerciante de Paita (7/04/1823) a Tomás Diéguez Florencia cuando este era diputado por Trujillo en el primer congreso constituyente:

... hacer quemar los reglamentos condenados que rigen a estas aduanas, porque con sus leyes se están perjudicando no solo a los comerciantes, sino a los pobres infelices que trayendo o introduciendo cuatro trapos... se los quitan decomisándoles unas cantidades que no llegan a cincuenta pesos... ${ }^{79}$

A estas confiscaciones habría que añadir los cupos y donativos que fueron exigidos por la superioridad. Ello no fue privativo del espacio norte, pues el descontento por el expolio de dinero era común en todo el territorio del Perú independiente, e inclusive hubo quienes, dentro de los grupos de poder, se rehusaron a cumplir los cupos desconociendo la autoridad de la cual emanaban aquellas disposiciones ${ }^{80}$.

Mientras todas estas cuestiones acontecían en el norte, en junio de 1823 las fuerzas realistas demostraron una vez más su poder pues el general Canterac ocupó la ciudad de Lima. Días antes de esta invasión, el presidente del Perú, José de la Riva Agüero, y el congreso constituyente se refugiaron en el Real Felipe del Callao. Estando aquí, se decidió que tanto el presidente como algunos ministerios y congresistas se dirigieran a Trujillo. Se pusieron de manifiesto las grandes diferencias y desavenencias entre el presidente y el congreso. Luego de varios decretos en que se le fue despojando de sus funciones, el congreso decidió destituir a Riva Agüero - más adelante sustituirlo por Torre Tagle- y hacer efectiva esta resolución cuando Riva Agüero y demás autoridades estuvieran en Trujillo. Una vez en el norte, Riva Agüero desconoció la destitución, apresó a los congresistas opositores, nombró un senado en esta ciudad y empezó a gobernar como presidente legítimo. Se inauguró así un gobierno paralelo en Trujillo en claro enfrentamiento con la ciudad de Lima ${ }^{81}$.

Esta situación marcó un antes y un después en la historia del norte peruano. Trujillo se convirtió en la cabeza de la república al ser la sede del gobierno «legítimo». Así lo decía la Gaceta del Gobierno del Perú que se

recurrente en algunas comunicaciones de los caudillos peruanos, como fue el caso de Agustín Gamarra con José de la Riva Agüero. Hernández García, 2019: 217.

${ }^{79}$ AGN, CTD, carpeta 8, caja 28, año 1823, doc. 81.

${ }^{80}$ Nos estamos refiriendo al cabildo catedralicio de Lima. El presidente José de la Riva Agüero y Sánchez Boquete, solicitó al clero regular y secular limeño el empréstito de 20.000 pesos. Tres miembros del cabildo se rehusaron: «Dichos Señores contestaron no reconocer más autoridad en el particular que el Soberano Congreso», Archivo Arzobispal de Lima, Lima (AAL), Serie Emancipación, Correspondencia, leg. 1. exp. 12, año 1823 (EC. 1. 12), fol. 3-3v. ${ }^{81}$ Vargas Ugarte, 1971. Paz Soldán, 1962. Basadre Grohmann, 1983. 
empezó a publicar en esa ciudad: «Ninguna población tenía más derecho para ser en las circunstancias la cabeza de la República que esta, cuyos servicios a la causa de la Libertad fueron tan singulares en el tiempo en que más se necesitaba de ellos» ${ }^{82}$. En ese preciso momento, Trujillo marcó una distancia considerable con el resto del Perú, argumentando que, por derecho, le correspondía liderar la república peruana al haber contribuido significativamente a la independencia. El norte se puso del lado de aquel líder político que estaba garantizando esa primacía con su presencia y con sus acciones.

A través de oficios y demás comunicaciones, los cabildos y autoridades norteñas mostraron su respaldo a Riva Agüero y su rechazo al gobierno y congreso de Lima. El Perú independiente se polarizó. Muy significativa es la petición de la municipalidad de Huaraz:

... pide a V.E [Riva Agüero]... la continuación del Senado [de Trujillo] cuya autoridad ha reconocido... en caso de no accederse a su petición, desde ahora... se separan del pueblo de Lima, que no tiene privilegio alguno para sujetar a los demás, sus iguales, a sus caprichos o voluntad ${ }^{83}$.

La defensa que el norte hizo de Riva Agüero podría afirmarse que se identifica con su propia lucha por una mayor visibilidad en el contexto político nacional, era la consolidación de la primacía que habían adquirido al proclamar la independencia antes que la capital. Desde esta dimensión, la presencia de Riva-Agüero en Trujillo va mucho más allá de la organización de la campaña militar desde el norte o de su propia lucha contra el gobierno limeño ${ }^{84}$. Riva Agüero representó para el norte peruano una gran reivindicación política y la posibilidad, por primera vez en su historia, de ser la cabeza del Perú. Esta situación cambió cuando Riva Agüero fue capturado, en noviembre de 1823, acusado de traidor a la patria y enviado al exilio.

Lima volvió a ser el centro del Perú independiente, pero en febrero de 1824 cayó una vez más en poder de los realistas. Y nuevamente el norte peruano, ahora bajo el liderazgo de Simón Bolívar, volvió a ser un punto importante desde donde hacer la resistencia.

${ }^{82}$ Gaceta del Gobierno del Perú, 1967: 417. La cursiva es nuestra.

${ }^{83}$ Puente Candamo y Deustua Pimentel, 1976: 485.

${ }^{84}$ Hernández García, 2019: 143. En este libro se incluye un epígrafe donde se estudia en profundidad la relación entre Riva Agüero y el norte del Perú. Un resumen sucinto de la trayectoria de Riva Agüero, en Hernández García, 2020: 31-38. Un artículo que incide en la capacidad de convocatoria de Riva Agüero sobre todo en los andes norcentrales: Montoya, 2020: 365-413. 


\section{REFLEXIONES FINALES}

Para enero de 1821 , casi todo el norte peruano era patriota. Si bien la mayoría de proclamaciones de independencia fueron resultado de una conciliación, en toda esta historia están presentes por igual el entusiasmo por la causa patriota y la adhesión a la causa realista. La primera se hace más evidente en unas provincias que en otras, movilizándose los patriotas en el momento decisorio a través de los cabildos. Y respecto a los partidarios de la causa realista, queda por analizar aún el hecho de que también, en medio de estos triunfos patriotas discursivos o bélicos, hay un proceso de repliegue que llevaron a cabo los realistas en todo ese espacio, repliegue que muchas veces significó algún tipo de resistencia. Algunos de estos realistas fueron los que destacaron en las contrarrevoluciones de Cajamarca y Maynas, es decir, tuvieron una actuación más directa en la guerra, con las armas o con su palabra ${ }^{85}$. Otros, se apartaron de la política e hicieron resistencia de manera solapada. Es este un nivel más dentro de toda la complejidad del momento, puesto que las proclamaciones de independencia en el norte fueron el inicio de un nuevo sistema de gobierno, pero la sociedad siguió igual de conectada, en el sentido de que la guerra, cuando se radicalizó, atacó a sus componentes y activó mecanismos de defensa en favor de quienes antes habían formado parte de la sociedad sin mayores problemas ${ }^{86}$. Desde este punto de vista, el norte fue una región de gran combustión social y política.

La intendencia de Trujillo, a diferencia de otros pueblos y ciudades de la sierra central que volvieron a estar bajo el control de los realistas a lo largo de la guerra, mirándola en bloque, proclamó su independencia y fue el único espacio que se mantuvo independiente hasta el final de la guerra ${ }^{87}$. Pero internamente no fue un frente homogéneo. Como hemos visto, hay muchos ángulos de análisis y niveles de complejidad que habría que seguir desentrañando para acercarnos a una mirada más integral del proceso regional y nacional de la independencia del Perú.

Si bien en las proclamaciones de independencia lo que se advierte es una fragmentación, un norte que proclama localmente su opción patriota, cuando

${ }^{85}$ Fue el caso del obispo de Maynas, Hipólito Sánchez Rangel, quien, desde Perú, Brasil y luego desde España, siguió escribiendo en contra de la independencia.

${ }^{86}$ La persecución contra los peninsulares se inició en la intendencia de Trujillo luego de proclamada la independencia. En esta línea destaca el peninsular Joaquín de Helguero y Gorgoya, avecindado en Piura, quien hizo a su manera una resistencia subrepticia contra el gobierno de la patria al contribuir a que peninsulares y/o realistas se refugiaran en su hacienda, algunos de ellos venían desde Guayaquil. Hernández García, 2008: 332.

${ }^{87}$ Sobrevilla, 2013: 262. 
se habla de las contrarrevoluciones realistas sí parece haber una conexión entre los espacios a los que se piensa llegar. Ahí radica la peligrosidad de estos movimientos. Además, estos, a su vez, buscan la conexión con un centro mayor: la sierra central, donde se halla el virrey La Serna. A esto nos referíamos cuando mencionábamos que el norte tenía fisuras. Maynas y Cajamarca son centros donde el liderazgo patriota y el liderazgo realista combaten por igual. La victoria patriota en las localidades sublevadas supone la consolidación de la independencia norteña con derramamiento de sangre y represión.

Una larga tradición de defensa de sus espacios de control se puso de manifiesto durante el gobierno independiente. En ninguna de las provincias norteñas hubo grandes cambios en la nómina de autoridades del gobierno de la nueva patria; es más, algunas ciudades interpusieron oficios y reclamos para intentar mantener el statu quo tanto en lo político como en lo económico. Por ello la presencia de autoridades extrañas a la localidad o al vecindario — «foráneas» - se relacionaba con autoritarismo, despotismo, arbitrariedad. Ello desdibujaba al Perú independiente. Es importante tener en cuenta estas perspectivas locales en un momento de legitimación de la causa patriota y del nuevo gobierno. Estamos en una etapa fundante donde la causa nacional necesitaba ganar prestancia política general; eso solo se conseguía con la legitimidad reconocida en todo el territorio, en todas las regiones. La historia de Trujillo y Riva Agüero, en buena cuenta, resume esta realidad.

Una gran extensión territorial - el norte peruano- no reconoció la autoridad de la ciudad de Lima, se distanció de la ex capital virreinal y decidió optar por José de la Riva Agüero, esto es, por un limeño que reivindicaba, por primera vez desde la proclamación de la independencia, a la región. Es sugerente que el norte apoye a Riva Agüero afincado en Trujillo, y no a Torre Tagle, considerando que este último había liderado la proclamación de la independencia norteña. Pero ahora Torre Tagle representaba a la facción limeña que no respetaba la decisión política de una de las regiones más importantes, la que primero contribuyó a la causa patriota. El Perú independiente se polarizó entre los partidarios de Riva Agüero y de Torre Tagle, situación que acabó con la prisión de Riva Agüero. Aunque esta historia fue efímera, duró lo suficiente como para dejar claro que otro gran problema camino a la consumación de la independencia en Junín y Ayacucho y a la consolidación de la república, era el tema de la afirmación de las voluntades políticas en una misma dirección. Los siguientes años Lima tuvo el timón de la república, pero los problemas internos continuaron. Poco 
tiempo después nuevamente las regiones, y un norte más amplio, volvieron a tener protagonismo ${ }^{88}$.

\section{BiBLIOGRAFÍA}

Aldana, Susana, "Un Norte y un Gran Norte para el Bicentenario. Reflexiones en torno a la independencia nacional desde la región", Francisco San Martín Baldwin y Victoria Diéguez (eds.), Trujillo Capital de la Independencia del Perú, Trujillo, Comisión Regional del Bicentenario La Libertad, 2020: 27-86.

Anna, Timothy, La caída del gobierno español en el Perú. El dilema de la independencia, Lima, Instituto de Estudios Peruanos, 2003.

Antología de la Independencia del Perú, Comisión Nacional del Sesquicentenario de la Independencia del Perú, Lima, 1972.

Ayrolo, Valentina (comp.), Estudios sobre clero iberoamericano, entre la independencia y el Estado-Nación, Salta, Universidad Nacional de Salta/CEPIHA (Centro Promocional de las Investigaciones en Historia y Antropología), 2006.

Bonilla, Heraclio, Chaunu, Pierre y Halperin, Tulio, La independencia en el Perú, Lima, Instituto de Estudios Peruanos/Campodónico Ediciones S.A., 1972.

Buller, Carlos, "Pumacahua en Arequipa, la incursión ambigua", Scarlett O'Phelan Godoy (ed.), 1814: la junta de gobierno del Cuzco y el sur andino, Lima, Pontificia Universidad Católica del Perú/Fundación M. J. Bustamante de la Fuente/ Instituto Francés de Estudios Andinos, 2016: 385-408.

Centurión Vallejo, Héctor, "La independencia de Trujillo (Apuntes para la historia de Trujillo 1800-1821)", Revista Universitaria, 21-22 (Trujillo, 1962): 1-155.

Chust, Manuel y Rosas, Claudia (eds.), El Perú en Revolución. Independencia y guerra: un proceso, 1780-1826, Castellón de la Plana, Universitat Jaume I/El Colegio de Michoacán, 2017.

Contreras, Carlos y Glave, Luis (eds.), La independencia del Perú, ¿concedida, conseguida, concebida?, Lima, Instituto de Estudios Peruanos, 2017.

Contreras Carranza, Carlos y Hernández García, Elizabeth (eds.), Historia económica del norte peruano. Señorios, haciendas y minas en el espacio regional, Lima, Banco Central de Reserva del Perú/Instituto de Estudios Peruanos, 2017.

Enríquez, Lucrecia, Historia, memoria y olvido del 12 de febrero de 1818. Los pueblos y su declaración de la independencia de Chile, Rosario, Prohistoria ediciones, 2018.

\footnotetext{
${ }^{88}$ Nos referimos a la Confederación Perú-Bolivia (1836-1839). El Perú y Bolivia se unieron en un gran proyecto, dividiéndose la Confederación en Estado NorPeruano, Estado SurPeruano y Estado Boliviano.
} 
Escudero Ortíz de Zevallos, Carlos, José Bernardo de Tagle y Portocarrero. Apuntes biográficos, Trujillo, Imprenta Editora Gráfica Real S.A.C., 2020.

Espinoza Soriano, Waldemar, "Reacción de los indígenas de Cajamarca frente a la Independencia de Trujillo y Lima, 1821-1822", Lima, Revista Investigaciones Sociales/Universidad Nacional Mayor de San Marcos, 2000.

Estenssoro, Juan Carlos y Méndez, Cecilia (eds.), Narra la independencia desde tu pueblo 1, Lima, Instituto Francés de Estudios Andinos/IEP, 2017.

Figueroa Luna, Guillermo, "Los indios y la plebe contra la elite en la independencia lambayecana", UMBRAL. Revista de Educación, Cultura y Sociedad, FACHSE (UNPRG), V/9-10 (Lambayeque, diciembre 2005): 22-37.

Flores Guzmán, Ramiro, "El enemigo frente a las costas. Temores y reacciones frente a la amenaza pirata, 1570-1720", Claudia Rosas Lauro (ed.), El miedo en el Perú. Siglos XVI al XX, Lima, Pontificia Universidad Católica del Perú, 2005: 33-50.

Flores Guzmán, Ramiro, "La complejidad del proceso de construcción regional: los casos de Trujillo y Arequipa durante la época colonial", Cristina Mazzeo (ed.), Las relaciones de poder en el Perú. Estado, regiones e identidades locales, siglos XVII-XIX, Lima, Fondo Editorial de la Pontificia Universidad Católica del Perú, 2011: 39-86.

Gaceta del Gobierno del Perú. Período de gobierno de Simón Bolívar, Tomo I, (1823, Lima y Trujillo), Caracas, Fundación Eugenio Mendoza, 1967.

Gerberging, Guillermo, Trujillo y la independencia del Perú. Palabras de homenaje pronunciadas en el "Club Trujillo", Lima, s. e., 1953.

Hernández García, Elizabeth, "Clérigos de provincia en busca de una prebenda: la lucha de los vecinos piuranos por una canonjía en el Perú tardocolonial (17801821)", Valentina Ayrolo (comp.), Estudios sobre clero iberoamericano, entre la independencia y el Estado-Nación, Salta, Universidad Nacional de Salta/CEPIHA (Centro Promocional de las Investigaciones en Historia y Antropología), 2006: $15-45$.

Hernández García, Elizabeth, "El marqués de Salinas, Francisco Javier Fernández de Paredes, y su permanencia en la clase dirigente piurana a inicios de la república (1785-1839)", Boletín del Instituto Francés de Estudios Andinos, 36/3 (Lima, 2007): 361-391.

Hernández García, Elizabeth, La élite piurana y la independencia del Perú. La lucha por la continuidad en la naciente república, 1750-1824, Lima, Instituto RivaAgüero/Pontificia Universidad Católica del Perú/Universidad de Piura, 2008.

Hernández García, Elizabeth, "Crisis de autoridad en una región periférica: la vecindad piurana frente a la nueva patria (Perú, 1821-1824)", Revista Andina, 12/52, (Cuzco, 2012):113-128. 
Hernández García, Elizabeth, "El movimiento insurgente del Cuzco fuera del Cuzco: las noticias de la revolución y su impacto en otros espacios", Scarlett O'Phelan Godoy (ed.), 1814: la junta de gobierno del Cuzco y el sur andino, Lima, Pontificia Universidad Católica del Perú/Fundación M. J. Bustamante de la Fuente/ Instituto Francés de Estudios Andinos, 2016: 315-337.

Hernández García, Elizabeth, "Un espacio regional fragmentado: el proceso de independencia y el norte del virreinato del Perú (1780-1824)", Manuel Chust y Claudia Rosas (eds.), El Perú en revolución. Independencia y guerra: un proceso, 1780-1826, Castellón de la Plana, Universitat Jaume I/El Colegio de Michoacán, 2017: 131-145.

Hernández García, Elizabeth, José de la Riva Agüero y Sánchez Boquete (1783-1858). Primer presidente del Perú, Lima, Fondo Editorial del Congreso del Perú/Instituto Riva-Agüero/Pontificia Universidad Católica del Perú, 2019.

Hernández García, Elizabeth, “José de la Riva Agüero y Sánchez Boquete. El liderazgo peruano en la independencia y en la naciente república", Presidentes y gobernantes del Perú republicano, Lima, Municipalidad Metropolitana de Lima, 2020: 31-38.

Hernández García, Elizabeth, "La expedición libertadora y el puerto de Paita: discurso, imagen y realidad", Ponencia en el Congreso Entre el Océano Pacífico y los Andes: La expedición libertadora en perspectiva histórica 1820-2020, Comisión Consultiva del Proyecto Bicentenario, Lima, noviembre de 2019, en prensa.

“Informe que Don José Ignacio Iturregui y Don José Leguía, próceres de la independencia nacional, presentaron en 1869 a la municipalidad de Lambayeque, sobre la proclamación de la libertad en esa población, el 27 de diciembre de 1820", Ricardo Miranda, Monografía general del departamento de Lambayeque, Chiclayo, Impresa en los Talleres Tipográficos El Tiempo, 1927.

Lanas Castillo, Paulo, "El partido de Tarapacá y el extremo sur del virreinato peruano durante la revolución cuzqueña de 1814”, Scarlett O'Phelan Godoy (ed.), 1814: la junta de gobierno del Cuzco y el sur andino, Lima, Pontificia Universidad Católica del Perú/Fundación M. J. Bustamante de la Fuente/Instituto Francés de Estudios Andinos, 2016: 409-433.

Mariátegui, Francisco Javier, Anotaciones a la Historia del Perú Independiente de Don Mariano F. Paz Soldán, Lima, Imprenta de El Nacional, 1869.

Mazzeo, Cristina (ed.), Las relaciones de poder en el Perú. Estado, regiones e identidades locales, siglos XVII-XIX, Lima, Fondo Editorial de la Pontificia Universidad Católica del Perú, 2011.

Miranda, Ricardo, Monografía general del departamento de Lambayeque, Chiclayo, Impresa en los Talleres Tipográficos El Tiempo, 1927. 
Montoya, Gustavo, "Conflictos y acuerdos entre la soberanía territorial de los pueblos del Norte, el Congreso y el gobierno de Riva Agüero", Francisco San Martín Baldwin y Victoria Diéguez (eds.), Trujillo Capital de la Independencia del Perú, Trujillo, Comisión Regional del Bicentenario La Libertad, 2020: 365-413.

Núñez, Estuardo (ed.), Colección Documental de la Independencia del Perú, Lima, Comisión Nacional del Sesquicentenario de la Independencia del Perú, 1971, tomo XXVII, vol. 2.

O'Phelan Godoy, Scarlett (comp.), La independencia del Perú. De los Borbones a Bolivar, Lima, Pontificia Universidad Católica del Perú/Instituto Riva-Agüero, 2001a.

O'Phelan Godoy, Scarlett, "Sucre en el Perú: entre Riva Agüero y Torre Tagle", Scarlett O'Phelan Godoy (comp.), La independencia del Perú. De los Borbones a Bolivar, Lima, Pontificia Universidad Católica del Perú/Instituto Riva-Agüero, 2001b: 379-406.

O'Phelan Godoy, Scarlett, La independencia en los andes. Una historia conectada, Lima, Fondo Editorial del Congreso del Perú, 2014.

O'Phelan Godoy, Scarlett (ed.), 1814: la junta de gobierno del Cuzco y el sur andino, Lima, Pontificia Universidad Católica del Perú/Fundación M. J. Bustamante de la Fuente/Instituto Francés de Estudios Andinos, 2016a.

O’Phelan Godoy, Scarlett, "Huánuco (1812) y el Cuzco (1814): entre la promulgación y la derogación de la constitución de Cádiz", Scarlett O'Phelan Godoy (ed.), 1814: la junta de gobierno del Cuzco y el sur andino, Lima, Pontificia Universidad Católica del Perú/Fundación M. J. Bustamante de la Fuente/Instituto Francés de Estudios Andinos, 2016b: 291-314.

O'Phelan Godoy, Scarlett, "El norte patriota y el sur realista. La división territorial del Perú en el contexto de la Independencia (1820-1824)", Scarlett O'Phelan Godoy y Ana Carolina Ibarra (comp.), Territorialidad y poder regional de las intendencias en las independencias de México y Perú, Lima, Fondo Editorial del Congreso del Perú, 2019: 391-437.

O'Phelan Godoy, Scarlett y Lomné, Georges (eds.), Voces americanas en las Cortes de Cádiz: 1810-1814, Lima, Instituto Francés de Estudios Andinos/Pontificia Universidad Católica del Perú, 2014.

O'Phelan Godoy, Scarlett y Saint-Geours, Yves (comp.), El Norte en la Historia Regional. Siglos XVIII-XIX, Lima, Instituto Francés de Estudios Andinos/Centro de Investigación y Promoción del Campesinado, 1998.

Ortemberg, Pablo, Rituales de poder en Lima (1735-1828). De la monarquía a la república, Lima, Pontificia Universidad Católica del Perú, 2014.

Ortíz de Zevallos, Javier (recop.), San Martín y Torre Tagle en la independencia del Perú, Lima, Centro de Documentación e Información Andina (CDI), 1982. 
Paz Soldán, Mariano Felipe, Historia del Perú Independiente. Primer Período 18191822, Buenos Aires, Instituto Nacional Sanmartiniano, 1962.

Pereyra Chávez, Nelson, "Los campesinos de Huamanga y la rebelión de 1814", Scarlett O'Phelan Godoy (ed.), 1814: la junta de gobierno del Cuzco y el sur andino, Lima, Pontificia Universidad Católica del Perú/Fundación M. J. Bustamante de la Fuente/Instituto Francés de Estudios Andinos, 2016: 339-361.

Pons Muzzo, Gustavo (recop.), Colección Documental de la Independencia del Perú, Lima, Comisión Nacional del Sesquicentenario de la Independencia del Perú, 1971, tomo VIII, vol. III.

Puente Candamo, José Agustín y Deustua Pimentel, Carlos (eds.), Colección Documental de la Independencia del Perú, Lima, Comisión Nacional del Sesquicentenario de la Independencia del Perú, 1976, tomo XVI.

Quijada, Mónica, Modelos de interpretación sobre las independencias americanas, México, Consejo Nacional de Ciencia y Tecnología/Universidad Autónoma de Zacatecas, 2005.

Rebaza, Nicolás, Anales del departamento de La Libertad en la guerra de la independencia, Trujillo, Editorial Ediciones Gráficas Industriales (edigrafi), 1971. [Primera edición 1898].

Reyes Flores, Alejandro, Hacendados y comerciantes: Piura, Chachapoyas, Moyobamba, Lamas, Maynas (1770-1820), Lima, Universidad Nacional Mayor de San Marcos, 1999.

Rizo-Patrón Boylan, Paul, "El conde de la Vega del Ren, sus conspiraciones y el movimiento rebelde de 1814", Scarlett O'Phelan Godoy (ed.), 1814: la junta de gobierno del Cuzco y el sur andino, Lima, Pontificia Universidad Católica del Perú/Fundación M. J. Bustamante de la Fuente/Instituto Francés de Estudios Andinos, 2016: 435-456.

Rizo-Patrón Boylan, Paul y Aljovín de Losada, Cristóbal, "La elite nobiliaria de Trujillo de 1700 a 1830", Scarlett O'Phelan Godoy e Yves Saint-Geours (comps.), El Norte en la Historia Regional. Siglos XVIII-XIX, Lima, Instituto Francés de Estudios Andinos/Centro de Investigación y Promoción del Campesinado, 1998: 241-293.

Rizo-Patrón Boylan, Paul y Salinas Pérez, Deynes, "Los diputados del virreinato del Perú en las Cortes de Cádiz: su dimensión social y regional”, Scarlett O'Phelan Godoy y Georges Lomné (eds.), Voces americanas en las Cortes de Cádiz: 18101814, Lima, Instituto Francés de Estudios Andinos/Pontificia Universidad Católica del Perú, 2014: 53-81.

Rodríguez Casado, Vicente y Lohmann Villena, Guillermo (eds.), Joaquín de la Pezuela. Virrey del Perú, 1816-1821. Memoria de gobierno, Sevilla, Escuela de Estudios Hispanoamericanos, 1947. 
Rojas Porras, Claudio, "La rebelión de 1814 en la ciudad de Huamanga", Scarlett O'Phelan Godoy, (ed.), 1814: la junta de gobierno del Cuzco y el sur andino, Lima, Pontificia Universidad Católica del Perú/Fundación M. J. Bustamante de la Fuente/Instituto Francés de Estudios Andinos, 2016: 363-384.

San Martín Baldwin, Francisco y Diéguez, Victoria (eds.), Trujillo Capital de la Independencia del Perú, Trujillo, Comisión Regional del Bicentenario La Libertad, 2020.

Sánchez, Susy, "Clima, hambre y enfermedad en Lima durante la guerra independentista (1817-1826)", Scarlett O'Phelan Godoy (comp.), La independencia del Perú. De los Borbones a Bolivar, Lima, Pontificia Universidad Católica del Perú/Instituto Riva-Agüero, 2001.

Sánchez, Susy, "Norte y sur: las milicias de Arequipa y Trujillo y la construcción de las diferencias regionales en el Perú (1780-1815)", Cristina Mazzeo (ed.), Las relaciones de poder en el Perú. Estado, regiones e identidades locales, siglos XVII-XIX, Lima, Fondo Editorial de la Pontificia Universidad Católica del Perú, 2011: 129-171.

Seminario Ojeda, Miguel, Piura y la independencia, Piura, Concejo Provincial de Piura, 1994.

Sobrevilla, Natalia, "Entre proclamas, actas y una capitulación: la independencia peruana vista en sus actos de fundación", Alfredo Ávila, Jordana Dym y Erika Pani (coords.), Las declaraciones de independencia. Los textos fundamentales de las independencias americanas, México, El Colegio de México/Universidad Nacional Autónoma de México, 2013: 241-274.

Temple, Ella Dunbar, "La revolución de Huánuco, Panatahuas y Huamalíes de 1812", Colección Documental de la Independencia del Perú, Lima, Comisión Nacional del Sesquicentenario de la Independencia del Perú, 1971, tomo III, vol. 1: IIIXCVII.

Vargas Ugarte, Rubén, Historia general del Perú, Lima, Editor Carlos Milla Batres, 1971, tomo VI.

Villanueva Urteaga, Horacio, Bolívar y la contribución de Cajamarca a la independencia del Perú, Caracas, Biblioteca Venezolana de Historia, 1974.

Fecha de recepción: 15 de enero de 2020.

Fecha de aceptación: 1 de septiembre de 2020. 


\section{Independence in northern Peru: the Intendancy of Trujillo and the patriotic option (1820-1823)}

This article offers an approach to analysing the independence process of Trujillo and the north of Peru, and revolves around a series of aspects: the existence of a prior political discourse acknowledging the locality; the events that conditioned the shift to the patriotic option; the proclamations of independence and counter-revolutions; local leaders; the political confrontations between provinces of the Intendancy of Trujillo in Peru that were already independent; and regional claims in the relationship between Trujillo and the capital of the Republic of Peru. With this in mind, it seeks to go further in examining the northern region that was first to proclaim its independence in the national context. On the road to both the proclamation and the consolidation of national independence, the intendancy of Trujillo was not a uniform entity.

Key words: Intendancy; Trujillo; northern Peru; independence; Peru; revolution; counterrevolution. 